\title{
Pemanfaatan Website Desa untuk Pembangunan: Perspektif Actor-Network Theory
}

\section{Utilization of Village Websites for Development: Actor-Network Theory Perspective}

\author{
Elsa Destriapani ${ }^{1, *}$, Sarwititi Sarwoprasodjo, Dwi Sadono
}

\author{
${ }^{1}$ Departemen Sains Komunikasi dan Pengembangan Masyarakat, Institut Pertanian Bogor, Bogor 16680, Indonesia \\ ${ }^{*}$ E-mail korespondensi: elsadestriapani@gmail.com
}

Received: September 17, 2021 | Revised: November 5, 2021 | Accepted: November 8, 2021| Online publication: November 11, 2021

\section{ABSTRACT}

Information and Communication Technology (ICT) is one of the determinants of village development. The presence of ICT is an enabling condition to accelerate the development process in rural areas. This study aimed to analyze the use of village websites for development based on the perspective of Actor-Network Theory in Warungbanten Village, Cibeber District, Lebak Regency, Banten Province. The method used in this research is qualitative with case studies. Data were collected by in-depth interviews, observation, and documentation. The technique of determining informants is done with a snowball (snowball). The results show that the use of village websites involves actors, and it occurs through translation which consists of several stages. The first is a problematization stage beginning with complaints and the village head's desire to open access to public information. The next stage, interest, is when the Head of Finance, ICT Volunteers, Banten Journalists, and local village assistants support the expectations of the village head. The enrolment stage is a division of roles in making the website so that it is connected to the Open SID community. Lastly, mobilization, it is when warungbanten.id has been used as the official website of the Warungbanten Village. Based on the translation process, the actors involved are classified according to their interests and influences, consisting of key players, subjects, context setters, and crowd. The effect of using village websites is to open access to village information, manage village data well to be more transparent, help communities promote local products, and get various awards.

Kata kunci: Actor Network Theory (ANT), ICT, translation, website

\section{ABSTRAK}

Teknologi Informasi dan Komunikasi (TIK) merupakan salah satu faktor penentu pembangunan desa. Kehadiran TIK menjadi kondisi pendukung (enabling condition) percepatan proses pembangunan di pedesaan. Tujuan dari penelitian ini adalah untuk menganalisis proses pemanfaatan website desa untuk pembangunan berdasarkan perspektif Actor Network Theory di Desa Warungbanten, Kecamatan Cibeber, Kabupaten Lebak, Provinsi Banten. Metode yang digunakan dalam penelitian ini adalah kualitatif dengan studi kasus. Pengumpulan data dilakukan dengan wawancara mendalam, observasi, dan dokumentasi. Teknik penentuan informan dilakukan dengan bola salju (snowball). Hasil penelitian menunjukkan pemanfaatan website desa melibatkan aktor-aktor dari berbagai pihak dan terjadi melalui translasi. Tahap pertama adalah problematisation diawali dengan keluhan dan keinginan kepala desa untuk membuka akses informasi publik. Selanjutnya tahap interessement terjadi ketika Kaur Keuangan, Relawan TIK, Jurnalis Banten, dan pendamping lokal desa mendukung harapan kepala desa. Tahap enrolment berupa pembagian peran dalam pembuatan website, sehingga terhubung dengan komunitas Open SID. Terakhir, mobilization adalah ketika warungbanten.id telah dijadikan sebagai website resmi Desa Warungbanten. Berdasarkan proses translasi tersebut aktor yang terlibat diklasifikasikan berdasarkan kepentingan dan pengaruhnya yang terdiri dari key player, subject, context setter, dan crowd. Efek dari penggunaan website desa adalah membuka akses informasi desa, mengelola data desa dengan baik sehingga lebih transparan, membantu masyarakat mempromosikan produk lokal, dan mendapatkan berbagai penghargaan.

Kata kunci: Actor Network Theory (ANT), TIK, translasi, website

Content from this work may be used under the terms of the Creative Commons Attribution-ShareAlike 4.0 International. Any further distribution of this work must maintain attribution to the author(s) and the title of the work, journal citation and DOI.

Published under Department of Communication and Community Development Science, IPB University and in association with Ikatan Sosiologi Indonesia

E-ISSN: 2302-7525 | P-ISSN: 2302-7157 


\section{PENDAHULUAN}

Lahirnya Undang-Undang No. 6 Tahun 2014 tentang Desa merupakan bentuk komitmen negara untuk menempatkan desa menjadi penggerak, sekaligus mengatasi ketimpangan akses dalam pembangunan. Undangundang desa tersebut mendorong kuatnya partisipasi dan kontrol masyarakat terkait proses pembangunan, termasuk dalam hal pembangunan teknologi informasi dan komunikasi (TIK) di pedesaan. Pemanfaatan TIK di pedesaan erat kaitannya dengan tata kelola pemerintahan desa. Kehadiran TIK menjadi kondisi pendukung (enabling condition) percepatan proses pembangunan di pedesaan. Berdasarkan penelitian terdahulu, TIK memiliki ragam manfaat yaitu digunakan untuk membangun transparansi, meningkatkan produktivitas, mempermudah pergerakan ekonomi, dan meningkatkan kualitas hidup (Adnan, 2020; Alhassan \& Adam, 2021; Kim et al., 2021; Uyar et al., 2021).

Perkembangan TIK di Indonesia, tidak terlepas dari persoalan kesenjangan digital (digital divide). Kesenjangan tersebut disebabkan oleh akses TIK, kemampuan SDM, dan pola fikir (mindset) masyarakat yang berbeda. Kesenjangan digital yang terjadi antara wilayah perkotaan dan pedesaan menambah jarak kemajuan pembangunan antara wilayah kota dan wilayah desa (Nasution, 2016). Review sistematis terhadap kajiankajian mengenai perkembangan digital di pedesaan yang dilakukan oleh Salemink et al., (2017) menyatakan bahwa komunitas pedesaan paling membutuhkan konektivitas digital yang lebih baik untuk mengimbangi keterpencilan mereka, tetapi mereka paling tidak terhubung. Masyarakat yang tinggal di pedesaan, kurang berpendidikan, berpenghasilan rendah, lanjut usia, dan disabilitas, merupakan kelompok sosial yang paling rentan mengakses TIK (Grishchenko, 2020; Tewathia et al., 2020; Zhou et al., 2011).

Menurut Sein et al., (2019), kajian TIK untuk pembangunan memiliki tiga kelompok teori, yaitu kelompok satu fokus pada teori pembangunan, kelompok dua fokus mengenai TIK dalam konteks pembangunan, dan kelompok tiga fokus pada proses transformatif yang menghubungkan TIK ke pembangunan. Ketiga kelompok teori tersebut muncul dari tiga konsep yang menjadi akar dari definisi area TIK untuk pembangunan, yaitu "TIK, Pembangunan, dan Untuk". Istilah "untuk" yang digunakan Sein et al., (2019) disebut proses transformasi yang menjadi fokus pada penelitian ini. TIK yang dimaksud dalam penelitian ini adalah website desa. Website desa memiliki potensi untuk mencapai tujuan pembangunan. Penelitian ini menggunakan teori Actor-Network Theory (ANT) untuk membantu menganalisis bagaimana website desa dapat mendorong pembangunan di pedesaan.

Teori ANT dikembangkan dari studi sosiologi di awal 1980-an oleh Michel Callon, Bruno La-tour, dan John Law. Teori ANT merupakan teori yang muncul sebagai antithesis teori Piere Bourdieu yang menyatakan bahwa aktor adalah individu manusia. Teori ANT memiliki penjelasan yang berbeda, seorang aktor didefinisikan sebagai sumber tindakan terlepas dari statusnya sebagai manusia atau non manusia. Hal tersebut dianggap sebagai gagasan radikal dalam konteks bahwa benda mati (misalnya seperti teknologi) juga memiliki agensi. Menurut Callon (1986), analisis jaringan sosio-teknis dilakukan melalui empat tahap yang saling terkait dari proses penerjemahan. Empat tahap tersebut adalah: (1) Problematisation, satu aktor atau lebih merumuskan masalahnya; (2) Interessement, semua aktor yang teridentifikasi di tahap pertama diberikan peran; (3) Enrolment, keberhasilan suatu kegiatan untuk menarik para aktor terlibat dalam suatu penyelesaian masalah; (4) Mobilization, ketika jaringan aktor terbentuk dengan aliansi yang lebih kuat.

Penelitian mengenai Actor Network Theory telah banyak dilakukan untuk memahami interaksi peran TIK untuk pembangunan dan proses yang terjadi ketika suatu inovasi teknologi seperti wireless project, project accountability, portal intranet, dan smart TV masuk ke dalam suatu sistem sosial (Aka, 2019; Burga \& Rezania, 2017; Mustika, 2018; Shim \& Shin, 2018; Thapa, 2011; Wang \& Yau, 2018). Penelitian Thapa (2011) misalnya yang mengeksplorasi bagaimana seorang aktivis sosial di tengah tantangan, memulai proyek nirkabel (wireless) untuk memfasilitasi layanan pendidikan dan perawatan kesehatan di daerah pegunungan. Studi tersebut mengidentifikasi aktor-aktor yang terlibat dalam proses pembentukan jaringan. Namun, penelitian yang dilakukan, belum ada yang melihat bagaimana penjelasan tepatnya aktor harus dilihat dan dianalisis. Untuk mengisi celah ini dan berkontribusi pada pemahaman yang lebih komprehensif mengenai peran berbagai aktor dan teknologi dalam mendorong pembangunan sosial, peneliti mengkombinasikan dengan teori sosial lainnya yaitu analisis pengaruh-kepentingan aktor.

Penelitian ini bertujuan untuk menganalisis proses pemanfaatan website desa untuk pembangunan berdasarkan perspektif Actor Network Theory di Desa Warungbanten, Kecamatan Cibeber, Kabupaten Lebak, Provinsi Banten. Desa Warungbanten dipilih karena sudah menggunakan website desa dalam proses kegiatan pemerintahannya. Berdasarkan data dari Badan Pusat Statistik (BPS) tahun 2019, jumlah desa/kelurahan di Indonesia yaitu 83.820 desa. Desa yang sudah menggunakan website desa berafiliasi dengan Open SID (Sistem 
Informasi Desa) per 5 Agustus 2021 sebanyak 6.117 desa. Artinya baru 7,3\% desa di Indonesia yang sudah menggunakan website desa dengan domain dari Open SID.

\section{METODE}

Paradigma penelitian yang digunakan adalah konstruktivis (Creswell, 2016) dengan kerangka teori ANT dan analisis pengaruh-kepentingan aktor untuk menjelaskan realitas yang dikaji. Penelitian ini menggunakan metode kualitatif dengan desain studi kasus (Yin, 2018). Kasus pada penelitian ini fokus pada proses pemanfaatan website Desa Warungbanten, Kecamatan Cibeber, Kabupaten Lebak, Provinsi Banten untuk pembangunan yang melibatkan aktor-aktor. Penelitian ini dilaksanakan pada bulan Februari - Mei 2021.

Teknik pengumpulan data dilakukan dengan observasi, wawancara mendalam, dan dokumentasi. Data yang terkumpul dari berbagai macam teknik tersebut dibandingkan, dicari persamaan dan perbedaannya, ditarik benang merahnya. Hal ini dilakukan untuk menentukan kredibilitas, validitas, dan reliabilitas data penelitian. Informan dipilih menggunakan snowball sampling yang terdiri dari Kepala Desa, Kaur Keuangan, Pengelola Website, Relawan TIK, Jurnalis Banten, Pendamping Lokal Desa, Pengrajin, Wakil Kasepuhan, Pemuda Desa, petani dan pengurus komunitas Open SID. Proses wawancara dilakukan secara tatap muka langsung, zoom meeting dan telepon.

Data yang terkumpul dianalisis dengan merujuk model interaktif Miles et al., (2014) terdiri dari: (1) Kondensasi data (data condensation), yaitu proses pemilihan, pemfokusan dan penyederhanaan dari transkrip wawancara; (2) Penyajian data (data display) dalam bentuk matriks; (3) Penarikan kesimpulan (verifying conclusions). Analisis data dalam penelitian kualitatifberlangsung bersamaan dengan bagian-bagian lain dari pengembangan penelitian kualitatif, yaitu pengumpulan data dan penulisan temuan. Aplikasi perangkat lunak QSR NVivo 12 digunakan untuk proses coding dan kategorisasi data transkrip wawancara. Proses coding dilakukan dengan menggunakan descriptive, in vivo process, evaluation, emotion, dan values coding (Miles et al., 2014).

\section{HASIL DAN PEMBAHASAN}

\section{Infrastruktur Digital di Desa Warungbanten}

Desa Warungbanten merupakan sebuah desa adat yang terletak di Kecamatan Cibeber, Kabupaten Lebak, Provinsi Banten. Desa Warungbanten masuk dalam komunitas kasepuhan Banten Kidul. Di Kabupaten Lebak terdapat dua jenis komunitas adat, yaitu Komunitas Baduy dan Komunitas Kasepuhan Banten Kidul. Komunitas Baduy relatif tertutup, sedangkan Komunitas Kasepuhan Banten Kidul sudah mulai terbuka, termasuk dalam hal teknologi. Jaringan operator seluler yang sudah ada di Desa Warungbanten saat ini diantaranya XL, Indosat, dan Telkomsel, namun jaringan operator belum merata ke seluruh Desa Warungbanten.

Desa Warungbanten sebelumnya menyandang status desa tertinggal. Infrastruktur digital seperti website dan media sosial belum terbangun dengan baik. Informasi tentang desa tidak terpublikasi secara luas, sehingga potensi dan kegiatan apapun tidak banyak diketahui oleh masyarakat luar desa. Pada tahun 2018, Desa Warungbanten masuk dalam kategori desa berkembang. Meskipun belum menyandang status desa maju, namun proses transformasi dari desa tertinggal menjadi desa berkembang patut diapresiasi.

\section{Proses Pemafaatan Website Desa untuk Pembangunan Administrasi dan Keterbukaan Informasi di Desa Warungbanten}

Menurut Sein et al., (2019), penelitian TIK untuk pembangunan ingin mencari tahu apa dan bagaimana peran TIK dalam pembangunan. Melalui analisis ANT dengan pendekatan interdisipliner, studi ilmu-ilmu sosial dan teknologi dianggap cocok untuk menjelaskan kaitan antara artefak dan konteks sosial (Mustika, 2018). Teori ANT memiliki beberapa posisi sentral yang dibahas, yaitu aktor, aktan, translasi, dan intermediari. Aktor dalam melakukan tindakan tidak lepas dari peranan aktor lain.

Aktor dalam teori ANT tidak hanya manusia tetapi juga non manusia. Aktor di dalam penelitian ini yaitu Kepala Desa, Relawan TIK, Pengelola Website, Kaur Keuangan, Ketua Badan Permusyawaratan Desa (BPD), Pendamping Lokal Desa, Wakil Kasepuhan, Website, Pengrajin, Facebook, Whats App, dan Telegram. Aktan adalah aktor pengendali yaitu Kepala Desa yang dapat mengendalikan aktor-aktor lain dalam proses 
pembangunan website. Intermediari merupakan aktor yang bertindak sebagai penghubung antara pihak aktor untuk memelihara relasi mereka. Whats App dalam hal ini menjadi intermediari.

Proses transformasi sosial dilihat sebagai translasi yang dipahami sebagai proses pembentukan jaringan (Sachari \& Prasetyo, 2013). Menurut Callon (1986) seperti sudah disebutkan di pendahuluan, proses translasi terdiri dari empat tahapan, yaitu (1) problematisation, (2) interessement; (3) enrolment, dan (4) mobilization. Proses translasi website desa untuk pembangunan administrasi dan keterbukaan informasi di Desa Warungbanten adalah sebagai berikut.

\section{Problematisation}

Momen problematisation adalah ketika suatu isu atau masalah dihadirkan oleh aktor untuk menjadi perhatian aktor-aktor lain, kemudian ditransformasikan ke dalam masalah-masalah yang didefinisikan oleh aktor-aktor lain. Masalah yang ingin diselesaikan oleh fokal aktor selaku Kepala Desa Warungbanten berawal dari keluhan dan harapan kepala desa untuk keluar dari ketertinggalan akses informasi yang dapat menghambat pembangunan desa. Kepala desa memilih menggunakan TIK dalam wujud website desa untuk mempercepat pembangunan desa. Hal ini seperti diungkapan oleh RH Kepala Desa Warungbanten sebagai berikut:

"Kita memerlukan website untuk menginformasikan kegiatan-kegiatan di desa agar masyarakat secara lebih luas dapat mengetahui apa saja yang sudah dilakukan Desa Warungbanten. Kita lebih kepada menginformasikan keluar, imbasnya mereka akan datang dan bersama-sama ikut mendukung pembangunan desa. Selain itu juga untuk mempertahankan sejarah dan mengabadikan peradaban. Jadi sebagai bukti, tidak ada sesuatu kegiatan yang hilang begitu saja tertelan waktu. Orang bisa saja berganti, tapi kegiatan kita jangan sampai hilang” (RH, Kepala Desa Warungbanten).

\section{Interessement}

Momen interessement terjadi ketika aktor lain terstimulasi, mulai mengikuti atau menolak isu/masalah dan mencoba meyakinkan aktor yang lain. Setelah kepala desa merumuskan masalah yang perlu dipecahkan, aktoraktor lain seperti Kepala Urusan Keuangan (Kaur Keuangan), Relawan TIK (RTIK), Jurnalis Banten, dan Pendamping Lokal Desa mulai mendukung. Proses pembuatan website diawali dengan komunikasi antara kepala desa dan kaur keuangan. Hal ini seperti diungkapkan oleh AN Kaur Keuangan yang sebelumnya sempat ditugaskan untuk mengelola website.

"Kepala desa komunikasi dengan saya agar membuat website dengan domain wordpress. Saya mengatakan kepada kepala desa, saya tidak bisa membuat website jika harus dari nol, jadi saya butuh bantuan teman saya. Tapi karena teman saya ada di Jakarta, jadi proses belajar pembuatan websitepun menjadi terhambat" (AN, Kaur Keuangan)

Meskipun proses pembuatan website menjadi terhambat, tidak membuat Kaur Keuangan menyerah. Kaur keuangan memberikan dukungan kepada kepala desa dalam pembentukan website dipengaruhi oleh kinerja kepala desa itu sendiri. Hal ini seperti diungkapkan oleh AN Kaur Keuangan.

"Yang membuat kita semangat bekerja adalah kita sudah melihat dari kinerja kepala desa itu sendiri. Benar-benar ingin memajukan desa. Jadi untuk menjadi kepala desa itu bukan untuk mengejar kekayaan, tapi benar-benar ingin memajukan desa. Jadi saya juga semangat untuk mencari tahu bagaimana membuat website, karena kebetulan kepala desa menugaskan saya untuk mencari-cari informasi tentang website. Mungkin karena sekolah saya di bidang IT”'(AN, Kaur Keuangan)

Kepala desa selain mengkomunikasikan gagasannya terkait website desa kepada aparat desa, juga beliau sampaikan kepada pendamping lokal desa. Hal ini seperti diungkapkan oleh EL Pendamping Lokal Desa.

"Inovasi Desa Warungbanten berangkat dari sebuah keluhan kepala desa yaitu bagaimana kita ingin mempublikasikan kegiatan dan potensi lokal kita. Dari keluhan tersebut saya memfasilitasi untuk membuat website desa, termasuk mulai merumuskan point-point apa saja yang perlu disiapkan untuk website" (EL, Pendamping Lokal Desa)

Pernyataan dari pendamping lokal desa juga didukung oleh pernyataan Relawan TIK Banten sebagai teman lama kepala desa ketika masih menjadi Ketua Pemuda Bujangga di Kasepuhan Kaolotan Cibadak, Desa Warungbanten. Mimpi besar kepala desa yang membuat relawan TIK semangat untuk ikut mengembangkan website di Desa Warungbanten diungkapkan oleh AP Relawan TIK Banten. 
"Saya tersentuh dan terinspirasi oleh mimpi besar Kepala Desa Warungbanten. Sebetulnya mimpi besarnya bukan hanya persoalan website desa, namun ada ruang yang ingin dikembangkan lebih jauh yaitu pemanfaatan ataupun pengelolaan potensi sumber daya alam yang ada dapat terpublikasi dan terdata dengan baik. Misalkan bagaimana jumlah keluarga miskin, pengrajin, potensi sumber daya, dan tatanan-tatanan lokal seperti aturan adat supaya tidak hanya diketahui oleh masyarakat lokal, tetapi juga terpublikasi dan menginspirasi banyak orang” (AP, Relawan TIK Banten)

\section{Enrolment}

Momen enrolment terjadi ketika aktor mulai saling mendelegasikan, menghitung kompetensi masing-masing, mengatasi resistensi, dan membangun peran. Para aktor seperti kaur keuangan dan pendamping lokal desa mencoba untuk merumuskan apa saja yang diperlukan untuk website. Di tengah kesulitan mereka membuat website, kemudian datang relawan TIK dari luar desa untuk memfasilitasi pelatihan pembuatan website. Hal ini seperti diungkapkan oleh AP Relawan TIK Banten.

"Pertama ya mengenalkan, ini websitenya sudah jadi (warungbanten.desa.id). Jadi websitenya mau seperti apa. Kita diawal itu sebenernya ketika mau membangun website itu kan selalu nanya ini seperti apa, biar kita bikinkan seperti yang diinginkan oleh teman-teman. Kita juga perlihatkan contoh-contoh yang lain. Ini seperti ini. Udah jadi bangunannya seperti itu. Kemudian yang kedua kita memperkenalkan tools-tools yang ada disitu. Setelah itu yang ketiga adalah kita membuat pelatihan. Pelatihan mengelola website. Apa yang perlu diberitakan. Pada saat itu kita melatih bagaimana cara menulis cepat bikin short news kabar singkat, apa yang dilakukan oleh desa terus kemudian dipublikasikan melalui web desa.” (AP, Relawan TIK Banten)

Selain pembuatan website, kepala desa juga mengajak jurnalis Banten untuk memberikan masukan terkait konten website, melalui pelatihan jurnalis kampung. Hal ini seperti diungkapkan oleh BL Jurnalis Banten.

"Karena Desa Warungbanten itu cukup lengkap tradisi adatnya juga cukup kuat gitu kan, makanya saya fokus disana dengan salah satu kegiatannya yaitu jurnalis kampung. Saya punya kegiatan atau labelnya jurnalis kampung. Ayo kita bikin kelas menulis bagaimana kita mengangkat potensi di desa ini kemudian kita upload ke media sosial, upload ke media online.” (BL, Jurnalis Banten)

Pada tahun 2015, Kementerian Komunikasi dan Informasi (Kominfo) mengeluarkan aturan tentang seluruh domain website desa di lingkungan pemerintahan harus menggunakan domain desa.id. Akan tetapi seiring berjalannya waktu, Desa Warungbanten lupa melakukan perpanjangan domain, sehingga warungbanten.desa.id tidak dapat digunakan. Perpanjangan domain pada saat itu memerlukan dokumendokumen yang harus dilampirkan. Namun, pemerintah desa akhirnya memutuskan untuk mencari alternatif website yang lain, karena warungbanten.desa.id tidak menyediakan portal penyimpanan data desa. Selanjutnya, pendamping lokal desa dan kaur Keuangan mencari informasi di facebook dan menemukan sebuah akun komunitas forum pengguna dan pegiat POpen SID (Sistem Informasi Desa).

Dari komunitas Forum Pengguna dan Penggiat Open SID, mereka mempelajari website desa melalui grup facebook dan telegram. Semua panduan untuk menginstal website mereka pelajari secara daring. Kelebihan Open SID adalah gratis (open source) karena dikembangkan bersama-sama oleh perangkat desa dan pegiat desa di Indonesia dan sudah legal berbadan hukum. Hal ini seperti diungkapkan oleh HW Sekertaris Jenderal Open SID.

"Open SID berawal dari tahun 2016 yang dikembangkan bersama komunitas Forum Pengguna dan Pegiat Open SID di facebook. Banyak penggiat dan kontributor yang ikut terlibat dalam pengembangan Open SID. Kemudian tahun 2018, komunitas semakin membesar dan desa-desa sudah banyak menggunakan Open SID. Akhirnya kami membuat sebuah kelembagaan supaya resmi masuk ke desadesa. Dari situlah disepakati namanya perkumpulan desa digital terbuka. Akhirnya awal tahun 2019, terbentuklah komunitas Open SID secara legal berbadan hukum (HW, Sekertaris Jenderal Open SID Pengurus komunitas Open SID)

\section{Mobilization}

Momen mobilization terjadi ketika jaringan aktor terbentuk dan memiliki eksistensi. Tahap ini sudah terbentuk situs web (website) desa dengan alamat warungbanten.id yang fungsinya bukan hanya untuk 
menginformasikan kegiatan-kegiatan atau produk lokal desa, tetapi juga digunakan untuk pengelolaan data dan administrasi desa. Hal ini seperti diungkapkan oleh AN Kaur Keuangan.

"Setelah bergabung dengan komunitas Open SID di facebook, akhirnya kami berhasil membentuk website dengan domain warungbanten.id. Jadi yang warungbanten.desa.id. bukan berarti ditutup, tapi kami lebih aktif mengupdate di warungbanten.id' (AN, Kaur keuangan)

Website desa diintegrasikan dengan akun facebook Desa Warungbanten dan Instagram Desa Warungbanten, sehingga memperluas jangkauan informasi. Akun facebook dan Instagram dikelola sendiri oleh Kepala Desa, sedangkan website dikelola oleh pengelola website yang merupakan aparat desa. Jaringan aktor yang terlibat dalam pembuatan website desa terbentuk dari relasi antar aktor dengan latar belakang berbeda-beda dalam memecahkan masalah dan menemukan solusi hingga terbentuknya website desa. Hal ini sejalan dengan penelitian Thapa (2011) yang mengkaji bagaimana seorang fokal aktor, ketua tim proyek nirkabel melibatkan aktor yang berbeda seperti aktivis sosial, dokter, pengusaha, relawan melalui proses interessement, enrolment dan mobilization untuk mengembangkan wilayah di Nepal.

\section{Analisis Pengaruh-Kepentingan Aktor dalam Pemanfaatan Website di Desa Warungbanten}

Konsep dasar dari pendekatan ANT adalah melihat aktor sebagai suatu jaringan yang berhubungan antara satu dengan yang lain. Salah satu kritik terhadap Actor-Network Theory (ANT) adalah ANT terlalu deskriptif dan gagal untuk menghasilkan penjelasan bagaimana tepatnya aktor harus dilihat dan dianalisis (Cresswell et al., 2010), sehingga peneliti menggunakan analisis pengaruh-kepentingan aktor untuk mendalami analisisnya. Aktor dalam hal ini dibedakan berdasarkan tingkat pengaruh dan kepentingannya. Pada analisis ini pengaruh aktor dilihat berdasarkan kekuasaan, keterampilan / keahlian dalam mengoperasikan TIK, dan kemampuan dalam memfasilitasi, sedangkan analisis untuk menentukan kepentingan dilihat berdasarkan harapan atau manfaat yang diinginkan oleh aktor.

Reed et al. (2009) mengelompokkan aktor menjadi empat yaitu (1) Key player, memiliki derajat pengaruh dan kepentingan yang tinggi; (2) Context setter, memiliki derajat pengaruh tinggi, kepentingan rendah; (3) Subject, memiliki derajat kepentingan tinggi, derajat pengaruh rendah; (4) Crowd, aktor dengan derajat pengaruh dan kepentingan rendah. Dari semua tahapan translasi proses transformasi website Desa Warungbanten, tingkat pengaruh dan kepentingan aktor diklasifikasikan pada Gambar 1.

\section{Kepentingan}

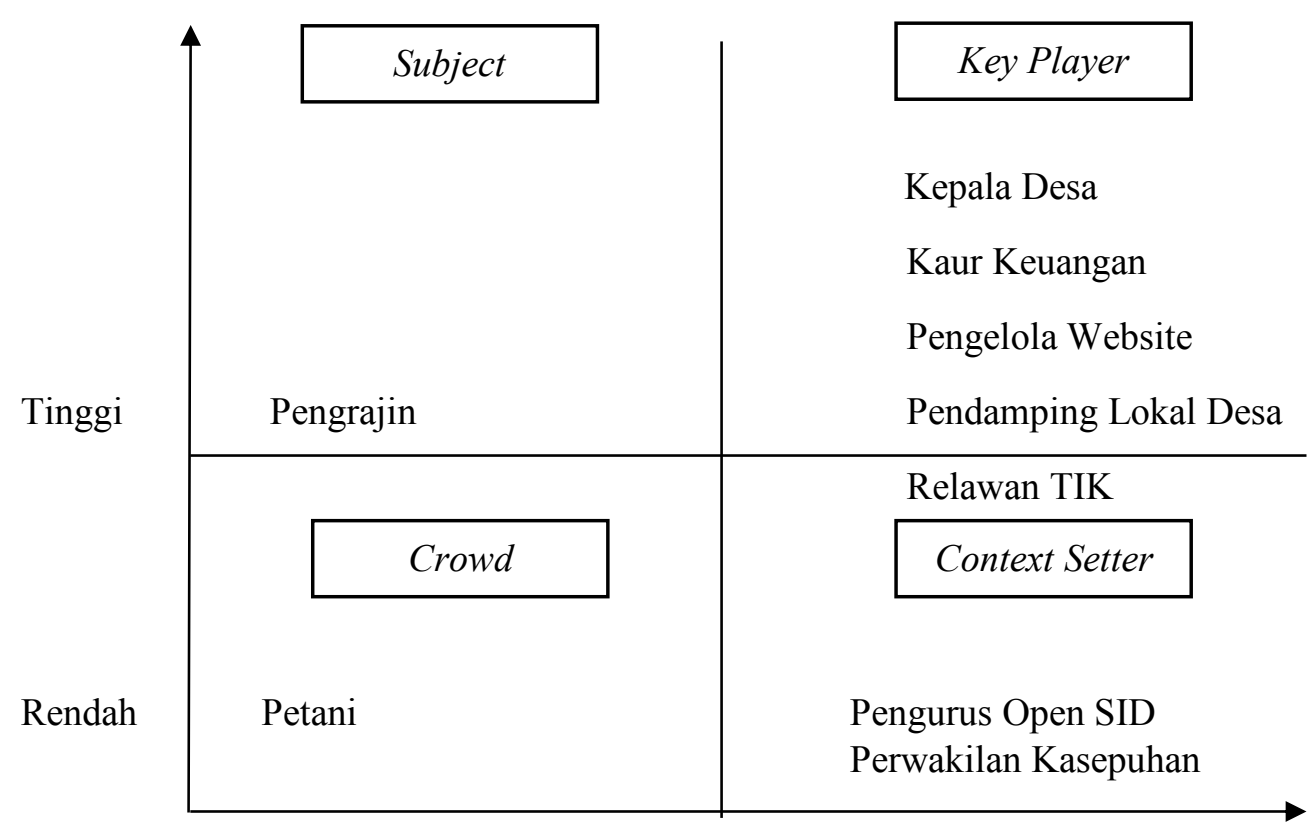

Pengaruh

Rendah Tinggi

Gambar 1. Matriks pengaruh-kepentingan aktor dalam pemanfaatan website di Desa Warungbanten 
Berdasarkan Gambar 1, aktor yang termasuk key player adalah kepala desa, kaur keuangan, pengelola website, pendamping lokal desa, relawan TIK, jurnalis Banten, dan pemuda desa. Kepala Desa memiliki harapan besar terhadap website untuk mempercepat pembangunan desa, disamping memiliki pengaruh yang besar untuk memutuskan melalui kebijakan desa. Kaur keuangan, pengelola website, dan pendamping lokal desa sebagai key player karena selain memiliki kemampuan yang tinggi untuk mengoperasikan website, ketiganya juga memiliki harapan yang tinggi agar website desa semakin luas penggunaannya.

Relawan TIK dan jurnalis Banten memiliki pengaruh yang tinggi karena dari awal ikut mendukung dengan memfasilitasi pelatihan pembuatan website, pembuatan short news, dan jurnalis kampung. Sampai saat ini mereka masih berkoordinasi dengan kepala desa. Pemuda desa juga masuk kategori key player, karena keterlibatan mereka dalam pembentukan website dan pelatihan jurnalis kampung.

Pengrajin termasuk kelompok subject karena meskipun mereka tidak memiliki pengaruh yang tinggi terhadap website desa, tetapi memiliki harapan yang tinggi terhadap manfaatnya. Pengrajin dapat memanfaatkan untuk mempromosikan hasil produk lokal seperti kerajinan kesenian (wayang, golek, dan angklung). Petani termasuk kelompok crowd, karena memiliki pengaruh dan kepentingan yang rendah ditandai dengan tidak memiliki fasilitas untuk mengakses website.

Kelompok context setter adalah pengurus Open SID dan perwakilan kasepuhan. Pengurus Open SID memiliki pengaruh yang tinggi karena merupakan pihak yang menyediakan aplikasi untuk website desa agar bisa diakses gratis, namun tidak berhubungan secara langsung dengan Desa Warungbanten sehingga kepentingannya rendah. Perwakilan kasepuhan sebagai context setter, memiliki pengaruh yang tinggi karena merupakan pihak yang dapat menyetujui atau menolak penggunaan TIK dalam hal ini website desa karena ada dalam lingkungan wilayah adat. Pada kasus ini, perwakilan kasepuhan mengapresiasi adanya inisiasi pembuatan website oleh kepala desa, seperti diungkapkan oleh WK Perwakilan Kasepuhan Kampung Cibadak, Desa Warungbanten. "Adanya website itu sangat bermanfaat terutama untuk kaum muda, jadi kami mendukung penuh langkah kepala desa tersebut. Kami juga bangga karena desa kami masuk kategori Desa Cantik(Desa Cinta Statistik) yang berawal dari website itu" (WK, Perwakilan Kasepuhan)

\section{Efek Penggunaan Website di Desa Warungbanten}

Website desa warungbanten.id memiliki tujuh menu tampilan, yaitu beranda, login, profil desa, pemerintahan desa, data desa, produk hukum, dan informasi publik. Pada menu login terdapat dua sub menu, yaitu menu administrator dan layanan mandiri. Menu administrator digunakan khusus untuk admin mengelola data, seperti data nama penduduk, jenis kelamin, jenis pekerjaan, pendidikan, dan agama. Petugas yang mengisi konten website adalah pengelola website. Jika ada pemuda desa yang tergabung dalam jurnalis kampung memiliki konten untuk diunggah ke website, mereka menghubungi pengelola website agar kontennya bisa dimuat di website setelah disetujui kepala desa.

Penggunaan website di Desa Warungbanten berimplikasi pada meningkatnya pengelolaan data desa dan pelayanan kepada masyarakat. Pengelolaan data desa semakin terstruktur dengan menggunakan warungbanten.id karena memiliki fungsi untuk menyimpan data penduduk beserta atribut-atributnya. Pembuatan surat dapat dilakukan secara otomatis, sehingga masyarakat yang akan membuat surat untuk kartu keluarga atau kartu tanda penduduk tidak perlu menunggu lama.

Efek penggunaan website yang lain adalah meningkatnya transparansi keuangan desa. Pemerintah desa lebih mudah membuat laporan pertanggungjawaban keuangan dan menyajikannya, sehingga informasi perencanaan dan pelaksanaan kegiatan pembangunan desa mudah diakses oleh masyarakat. Website desa juga berimpikasi pada meningkatnya produktivitas ekonomi lokal. Kepala desa memanfaatkan website untuk mempromosikan produk-produk lokal seperti gula merah dan kerajinan kesenian (wayang, angklung, golek), sehingga terjadi peningkatan penjualan. Hal ini seperti diungkapkan oleh RM (Pengrajin).

"Jelas, setelah Pak RH menjadi Kepala Desa jadi merasa lebih banyak yang pesan, dulu sebelum ada beliau tidak banyak yang pesan, kalo sekarang banyak yang pesan” (RM, Pengrajin).

Efek yang dirasakan oleh RM, juga dirasakan oleh MM. Hal ini seperti diungkapkan oleh MM sebagai berikut.

"Memang jauh beda, karena kepala desa yang sebelumnya, tiga orang yang sudah menjabat tidak ada yang menggerakkan ini. Baru Pak RH sekarang, bisa memajukan di bidang kerajinan, seperti kerajinan boboko, angklung, calung, dan biola yang saya produksi” (MM, Pengrajin) 
Relawan TIK juga mendukung pernyataan dari para pengrajin tersebut. Efek yang ditimbulkan oleh website menjadi fungsional, sebagai mana diungkapkan AP sebagai berikut.

"Jadi saat ini sudah mulai ada imbas dari digital ini ke hal yang lebih fungsional. Hasil pemetaan jaringan kerja pemetaan partisipatif (JKPP) bersama masyarakat Warungbanten. Disana banyak pengrajin gula, kemudian dari pengrajin gula diorganisir oleh kepala desa, dipromosikan melalui website dan media sosial yang ada. Itulah kemudian dari efek digital menjadi fungsional. Artinya bagaimana media digital ini membantu ekonomi masyarakat." (AP, Relawan TIK)

Website desa juga dapat memperluas informasi tentang desa ke khalayak luas, sehingga banyak pihak dari luar desa yang datang ke Desa Warungbanten untuk ikut membangun desa. Misalnya Yayasan Bina Desa yang datang untuk memberikan pelatihan pertanian organik, karena melihat postingan di website mengenai potensi Desa Warungbanten. Bermula dari website, sudah beberapa stasiun TV datang ke desa untuk meliput dan memberitakan potensi dan kegiatan-kegiatan desa. Hal ini sejalan dengan penelitian Mulyawati et al. (2016) dan Akbar et al. (2019) yang menunjukkan bahwa website desa efektif sebagai media penyebaran informasi pembangunan.

Keaktifan Desa Warungbanten dalam menggunakan website desa, menarik perhatian pemerintah pusat dan daerah. Hingga saat ini, penghargaan yang diterima oleh Desa Warungbanten adalah Penghargaan Ekshibisi Keterbukaan Informasi Publik dari Komisi Informasi Provinsi Banten tahun 2020 dan masuk kategori Desa Cinta Statistik (Cantik) tahun 2021 yang diseleksi oleh Badan Pusat Statistik Nasional. Dari 100 desa yang terpilih di Indonesia akan didampingi BPS agar menjadi desa yang berdayaguna dan mampu mengembangkan desa melalui data-data yang dimiliki.

\section{KESIMPULAN}

Pemanfaatan website di Desa Warungbanten terjadi melalui tahapan problematisation, interessement, enrolment, dan mobilization. Kehadiran website tersebut telah mengurangi kesenjangan digital yang terjadi di Desa Warungbanten. Berdasarkan proses penerjemahan, aktor yang terlibat diklasifikasikan berdasarkan minat dan kekuatannya dibagi menjadi key player, subject, context setter, dan crowd. Kepala desa merupakan key player yang mampu bekerjasama dengan aktor kunci lainnya dari dalam dan luar desa dalam pengembangan website desa. Efek dari penggunaan website desa yaitu pengelolaan administrasi data desa menjadi terstruktur sehingga pelayanan publik semakin baik serta informasi pengelolaan keuangan semakin transparan dan akuntabel. Selain itu, meningkatkan promosi produk lokal dan menarik pihak luar untuk ikut mendukung pembangunan desa. Penghargaan dari pemerintah pusat menjadikan aparatur Desa Warungbanten semakin semangat untuk mengoptimalkan peran website desa.

\section{UCAPAN TERIMA KASIH}

Penulis mengucapkan terima kasih kepada pemerintah Desa Warungbanten serta pihak-pihak lain yang telah mendukung penelitian ini. Penelitian ini dapat terlaksana dengan bantuan pembiayaan dari Kementerian Riset dan Teknologi/Badan Riset dan Inovasi Nasional (Ristek-BRIN) melalui skema Penelitian Tesis Magister (PTM) Tahun anggaran 2021.

\section{DAFTAR PUSTAKA}

Adnan, S. (2020). ICTs for Development: Building the Information Society by Understanding the Consumer Market. In J. Servaes (Ed.), Handbook of Communication for Development and Social Change. (pp. 9891012). Springer, Singapore. https://doi.org/https://doi.org/10.1007/978-981-15-2014-3_93

Aka, K. G. (2019). Actor-network theory to understand, track and succeed in a sustainable innovation development process. Journal of Cleaner Production, 225, 524-540. https://doi.org/10.1016/j.jclepro.2019.03.351

Akbar, M. F., Jaya, F. H., \& Putubasai, E. (2019). Implementasi Website Desa dalam Pemberian Pelayanan Informasi Pembangunan. Jurnal Teknologi Dan Komunikasi Pemerintahan, 1(1), 42-51.

Alhassan, M. D., \& Adam, I. O. (2021). The effects of digital inclusion and ICT access on the quality of life: 
A global perspective. Technology in Society. https://doi.org/10.1016/j.techsoc.2020.101511

Burga, R., \& Rezania, D. (2017). ScienceDirect Project accountability: An exploratory case study using actor - network theory. International Journal of Project Management, 35(6), 1024-1036. https://doi.org/10.1016/j.jproman.2017.05.001

Callon, M. (1986). Some Elements of a Sociology of Translation: Domestication of the Scallops and the Fishermen of St Briuec Bay. In J. Law (Ed.), Power, Action \& Believe: A New Sociology of Knowledge (pp. 196-229). Routledge.

Cresswell, K. M., Worth, A., \& Sheikh, A. (2010). Actor-Network Theory and its role in understanding the implementation of information technology developments in healthcare. BMC Medical Informatics and Decision Making, 10(1), 67. https://doi.org/10.1186/1472-6947-10-67

Creswell, J. W. (2016). Research Design. Pustaka Pelajar.

Grishchenko, N. (2020). The gap not only closes: Resistance and reverse shifts in the digital divide in Russia. Telecommunications Policy, 44(8), 1-15. https://doi.org/10.1016/j.telpol.2020.102004

Kim, J., Park, J. C., \& Komarek, T. (2021). The impact of Mobile ICT on national productivity in developed and developing countries. Information and Management. https://doi.org/10.1016/j.im.2021.103442

Miles, M. B., Huberman, A. M., \& Saldana, J. (2014). Qualitative Data Analysis (3rd ed.). Sage Publications.

Mulyawati, S., Muljono, P., \& Seminar, K. B. (2016). Efektivitas Website Desa sebagai Media Penyebaran Informasi Pembangunan Di Desa Malasari Kabupaten Bogor. IPB University.

Mustika, R. (2018). Inovasi Teknologi Portal Intranet Kominfo: Perspektif Actor Network Theory. Jurnal Komunikasi Indonesia, 4(1), 38-47. https://doi.org/10.7454/jki.v4i1.8877

Nasution, R. D. (2016). Pengaruh Kesenjangan DIgital terhadap Pembangunan Pedesaan (Rural Development). Jurnal Penelitian Komunikasi Dan Opini Publik, 20, 31-44.

Reed, M. S., Graves, A., Dandy, N., Posthumus, H., Hubacek, K., Morris, J., Prell, C., Quinn, C. H., \& Stringer, L. C. (2009). Who's in and why? A typology of stakeholder analysis methods for natural resource management. Journal of Environmental Management, 90(5), 1933-1949. https://doi.org/10.1016/j.jenvman.2009.01.001

Sachari, A., \& Prasetyo, F. (2013). Place Construction and Urban Social Transformation : an Actor Network Theory Analysis for Creative-Kampung Phenomena in Bandung. Habitecno International Seminar, November 2013, 230-239.

Salemink, K., Strijker, D., \& Bosworth, G. (2017). Rural development in the digital age: A systematic literature review on unequal ICT availability, adoption, and use in rural areas. Journal of Rural Studies, 54(October), 360-371. https://doi.org/10.1016/j.jrurstud.2015.09.001

Sein, M. K., Thapa, D., Hatakka, M., \& Sæbø, Ø. (2019). A holistic perspective on the theoretical foundations for ICT4D research. Information Technology for Development, 25(1), 7-25. https://doi.org/10.1080/02681102.2018.1503589

Shim, Y., \& Shin, D. (2018). Technological Forecasting \& Social Change Smartness in techno-nationalism? Combining actor-network theory and institutionalization to assess Chinese smart TV development. Technological Forecasting \& Social Change, August, 0-1. https://doi.org/10.1016/j.techfore.2018.09.004

Tewathia, N., Kamath, A., \& Ilavarasan, P. V. (2020). Social inequalities, fundamental inequities, and recurring of the digital divide: Insights from India. Technology in Society, 61, 1-11. https://doi.org/10.1016/j.techsoc.2020.101251

Thapa, D. (2011). The Role of ICT Actors and Networks in Development: The Case Study of a Wireless Project in Nepal. The Electronic Journal of Information Systems in Developing Countries, 49(1), 1-16. https://doi.org/10.1002/j.1681-4835.2011.tb00345.x

Uyar, A., Nimer, K., Kuzey, C., Shahbaz, M., \& Schneider, F. (2021). Can e-government initiatives alleviate 
tax evasion? The moderation effect of ICT. Technological Forecasting and Social Change. https://doi.org/10.1016/j.techfore.2021.120597

Wang, J. J., \& Yau, S. (2018). Case studies on transport infrastructure projects in belt and road initiative: An actor network theory perspective. Journal of Transport Geography, 71(January), 213-223. https://doi.org/10.1016/j.jtrangeo.2018.01.007

Yin, R. K. (2018). Case study research and applications: Design and methods. In Journal of Hospitality \& Tourism Research (Sixth, Vol. 53, Issue 5). https://doi.org/10.1177/109634809702100108

Zhou, Y., Singh, N., \& Kaushik, P. D. (2011). The digital divide in rural South Asia: Survey evidence from Bangladesh, Nepal and Sri Lanka. IIMB Management Review, 23(1), 15-29. https://doi.org/10.1016/j.iimb.2010.12.002 